\title{
Effects of Atorvastatin on Experimental Spinal Cord Ischemia-Reperfusion Injury in Rabbits
}

\author{
Ozgur KARDES ${ }^{1}$, Soner $\mathrm{CIVI}^{1}$, Kadir TUFAN ${ }^{1}$, Eser OZ OYAR ${ }^{2}$, Suna OMEROGLU ${ }^{3}$, Sukru AYKOL ${ }^{4}$ \\ ${ }^{1}$ Baskent University, Faculty of Medicine, Department of Neurosurgery, Adana, Turkey \\ ${ }^{2}$ Katip Celebi University, Faculty of Medicine, Department of Physiology, Izmir, Turkey \\ ${ }^{3}$ Gazi University, Faculty of Medicine, Department of Histology and Embryology, Ankara, Turkey \\ ${ }^{4}$ Gazi University, Faculty of Medicine, Department of Neurosurgery, Ankara, Turkey
}

\section{ABSTRACT}

AIM: Extent of secondary injury is the determinant of tissue destruction and functional worsening after primary spinal cord injury (SCI). Data have accumulated on alleviation of secondary injury in $\mathrm{SCl}$ from many studies on the subject. Besides its cholesterol lowering effects, statins are known to have anti-inflammatory and anti-oxidant effects which are the main targets of spinal cord research. This study aims to evaluate the effects of atorvastatin on experimental spinal cord ischemia-reperfusion injury.

MATERIAL and METHODS: Thirty adult male New Zealand rabbits were allocated into control, ischemia-reperfusion (I/R) and treatment groups. Treatment group received $5 \mathrm{mg} / \mathrm{kg}$ of atorvastatin via lavage for the preceding 14 days. Other groups received placebo during the same time period. After two weeks, animals in the I/R and treatment groups underwent abdominal temporary aorta occlusion for 30 minutes. Neurological condition of the animals was recorded during the 48 hours of observation. Afterwards, animals were sacrificed and levels of malondialdehyde, glutathione and nitric oxide in spinal cord tissue and plasma and the histopathological tissue changes were determined.

RESULTS: Animals in the treatment groups demonstrated significantly better results than the I/R group regarding biochemical markers. Neurological evaluation using the Tarlov scale demonstrated significantly better results at the $48^{\text {th }}$ hour in treatment group. Histopathological results were also better in the treatment groups.

CONCLUSION: Results of this study demonstrate the neuroprotective effects of atorvastatin. Atorvastatin has favorable effects on biochemical markers of oxidative stress in SCI. Further studies with larger cohorts and different time periods are also needed.

KEYWORDS: Atorvastatin, Ischemia/reperfusion injury, Statin, Spinal cord injury

\section{INTRODUCTION}

S pinal cord injury (SCl) is a mechanical insult followed by a secondary cascade of biologic events promoting permanent tissue damage. Excitotoxicity, oxidative stress and inflammatory response are the mediators of secondary injury, which is -theoretically- preventable $(5,16)$. In the central nervous system (CNS), ischemic traumatic injury, cell loss and neuronal dysfunction, is thought to be the result of glutamatemediated excitotoxicity, formation of reactive oxygen species
(ROS), and lipid peroxidation (43). Studies have demonstrated increased glutamate release, activation of glutamate receptors and accumulation of calcium result in increased glutamate $(3,21)$.

Statins are a group of drugs that competitively inhibit the 3-hydroxy-3-methyl-glutaryl-CoA (HMG-CoA) reductase, the first enzyme of the HMG-CoA reductase pathway. This inhibition impedes production of mevalonate, the next molecule in the cascade producing cholesterol. This action ultimately 
reduces cholesterol in the organism. They are used for treatment of dyslipidemias and prevention of cardiovascular diseases $(15,45)$. On last two decades, extensive research has focused on these agents, revealing their neuroprotective and immunomodulatory effects $(15,29,36,45,50)$.

Some benefits of statins in primary and secondary ischaemic stroke prevention are established. Although the neuroprotective effects of statins are partially understood; correcting blood flow, reducing coagulation, reducing oxidative damage and immune regulatory effects seem to be the probable mechanisms $(15,29,36,45,50)$.

The aim of this study was to investigate the neuroprotective effects of a statin class agent -atorvastatin- on an experimental spinal cord ischemia-reperfusion injury model in rabbits.

\section{MATERIAL and METHODS}

The experimental protocol was evaluated and approved by the "Gazi University Medical Faculty, Ethics Review Committee". This study was performed at the Gazi University Faculty of Medicine, Experimental Research Center. Animals were handled as per the laboratory animal welfare guidelines.

A cohort of 30 adult male New Zealand rabbits weighing between $2.5-3 \mathrm{~kg}$ was divided into control, ischemia-reperfusion $(\mathrm{I} / \mathrm{R})$ and treatment groups. Animals were randomized and all evaluations were blind to the investigators.

Animals were kept in standard laboratory settings with free access to food and water. Animals in the treatment group received $5 \mathrm{mg} / \mathrm{kg}$ of pure atorvastatin (Abdi Ibrahim, Istanbul, Turkey) via gastric lavage for the preceding 14 days. In the I/R group any treatment was given for the same time period $I / R$ injury.

Anesthesia was induced by intramuscular administration of $70 \mathrm{mg} / \mathrm{kg}$ ketamine hydrochloride (Ketalar, Pfizer; Istanbul, Turkey) and $5 \mathrm{mg} / \mathrm{kg}$ xylazine (Rompun, Bayer; Istanbul, Turkey) and allowed breath spontaneously. Body temperatures were maintained as appropriate with a heating pad. The arterial pressure and heart rate were monitored continually. The spinal cord ischemia-reperfusion model, which was described by Zivin and De Girolami (18), was used. After animals were placed in supine position operation area, shaved and cleaned with $10 \%$ polyvinylpyrolidone/iodine. The transperitoneal approach was used to expose the abdominal aorta. $150 \mathrm{U} / \mathrm{kg}$ heparin infusion for anticoagulation was performed five minutes before clamping. The aorta was cross clamped at two sites via two aneurysm clips (70 g closing force, Yasargil FE 721, Aesculap, Germany). Clips were placed under the surgical microscope $1 \mathrm{~cm}$ below the renal arteries and $1 \mathrm{~cm}$ above the bifurcation.

Thirty minutes later, the clips were removed and the regeneration of the blood flow was observed (11). The incision was closed in layers.

In the I/R group and the treatment group, the aorta was occluded for 30 minutes. Only laparotomy was performed in the control group. Two hours after the treatment, the animals were allowed free access to food and water. Credé's maneuver was performed to animals with neurogenic bladder at least two times a day 48 hours after surgical procedure. Animals were euthanized with a high dose of pentobarbital $(200 \mathrm{mg} / \mathrm{kg})$.

Forty-eight hours after the surgical procedure, a $10 \mathrm{cc}$ cardiac blood sample was obtained for biochemical analysis. Tissue samples were harvested from the spinal cord after T12-S1 total laminectomies. Spinal cord segments between L2 and L5 were used for biochemical analysis while segments between L5 and S1 were used for histopathological analysis. Levels of nitric oxide (NO), glutathione (GSH) and Malondialdehyde (MDA) were analyzed in spinal cord and plasma. The tissue MDA levels initially peaked 4 hours post-injury. By 12 hours, the MDA levels returned to baseline. A second increase was observed from 24 hours to 5 days (12).

Histopathological evaluation was described in another study previously Briefly, after fixing spinal cord specimens in $10 \%$ buffered formalin for a period of ten days, paraffin embedding was performed. Five-micrometer-thick sections were cut axially using a microtome (RM 2245, Leica) for hematoxylin and eosin (H\&E) staining. Slides were evaluated under a light microscope (DMI 4000 B Leica) by a histologist blinded to the groups (31).

Axonal damage, neuronal degeneration and glial cell infiltration were analyzed as histopathological changes. Axonal damage was graded as G0 (normal), G1 (mild swelling and vacuolization in axons), G2 (severe swelling and vacuolization in axons). The intensity of degenerated neurons was calculated in each field. Glial cell infiltration was graded as $+1,+2$, +3 and +4 according to their intensity in each field (31).

Spinal cord and plasma levels of NO, GSH and MDA were analyzed. After the last postoperative neurological examination blood samples were collected through a cardiac puncture.

All of the rabbit spinal cord and serum samples in each group were used for biochemical analysis. Whole spinal cord tissues were washed 2 times with cold saline. It was placed in glass bottles, labeled and stored until worked at the deep freeze. In blood and tissues NO, GSH and MDA levels were measured $(2,9,33,37)$.

Measurement of Serum MDA: $500 \mathrm{ml}$ of serum into one milliliter of thiobarbituric acid/ trichloroacetic acid/hydrochloricacid were added. It was vortexed for 30 seconds in microcentrifugation tube. After centrifuging the mixture at $10,000 \mathrm{rpm}$ for 5 minutes, the supernatant was placed into a glass tube. Ten microliters of butylated hydroxytoluene and this mixture added in the tube and boiled for 15 minutes. The sample was then compared with distilled water and was evaluated Elisa reader at $532 \mathrm{~nm}$, and the MDA level was calculated using the following formula: Plasma MDA =adsorbance $\times 19.2 \mathrm{nmol}$ $\mathrm{MDA} / \mathrm{mL}$ plasma (33).

Measurement of Serum GSH: Serum placed into a microcentrifuge tube $(500 \mathrm{ml})$ and $1 \mathrm{ml}$ of hydrochloric acid/Na dodesyl sulfate/ethylenediamine tetraacetic acid $(\mathrm{pH}=8.2)$ was centrifuged at $25^{\circ} \mathrm{C}$ and $12,000 \mathrm{rpm}$ for 5 minutes. Dithio Nitrobenzoic acid was maintained at $37^{\circ} \mathrm{C}$ for 20 minutes $(0.3$ 
$\mathrm{mM}$ ) was added to the supernatant. The sample was read at $405 \mathrm{~nm}$ in an enzyme-linked immunosorbent assay reader (2).

Measurement of Tissue MDA and GSH: Tissue MDA and GSH analysis was performed as described by Aykac, Casini and $\mathrm{Oz}$ previously. Five hundred milligrams of tissue was homogenized by $5 \mathrm{~mL}$ ice-cold $10 \%$ trichloroacetic acid solution; then the homogenate was centrifuged at $3000 \mathrm{rpm}$ for 10 min and the supernatant MDA level was assayed by thiobarbituric acid reactive substance formation, after which the GSH level was measured by the modified Ellman method. As previously reported, $750 \mu \mathrm{L}$ of supernatant was added to an equal volume of $0.67(\mathrm{w} / \mathrm{v})$ thiobarbituric acid and heated to $100^{\circ} \mathrm{C}$ for 15 minutes $(2,9,40)$.

The absorbance of the samples was measured at $533 \mathrm{~nm}$. The LP level was expressed in terms of the MDA equivalent using an extinction coefficient of $1.56 \times 10^{-5} \mathrm{~cm}^{-1} \mathrm{M}^{-1}$. To determine the GSH levels, $0.5 \mathrm{~mL}$ of supernatant was added to $2 \mathrm{~mL} 0.3$ $\mathrm{M} \mathrm{Na}{ }_{2} \mathrm{HPO}_{4} \cdot 2 \mathrm{H}_{2} \mathrm{O}$ solution. Next, $0.2 \mathrm{~mL}$ dithiobisnitrobenzoic acid solution $(0.4 \mathrm{mg} / \mathrm{mL}$ in $1 \%$ sodium citrate) was added and absorbance at $412 \mathrm{~nm}$ was measured immediately after mixing $(2,9,40)$.

Measurement of Nitrate Levels: Nitrate levels analysis was performed as described by Miranda and Oz previously. The nitrate levels were obtained using an enzyme-linked immunosorbent assay reader by vanadium chloride ( $\mathrm{VCl} 3$ )/Griess assay. Prior to nitrate determination, tissues were homogenized in five volumes of phosphate-buffered saline $(\mathrm{pH} 7.5)$ and centrifuged at $2000 \mathrm{~g}$ for 5 minutes. Then $0.25 \mathrm{~mL}$ of $0.3 \mathrm{M}$ $\mathrm{NaOH}$ was added to $0.5 \mathrm{~mL}$ supernatant. After incubation for 5 minutes at room temperature, $0.25 \mathrm{~mL}$ of $5 \%(\mathrm{w} / \mathrm{v}) \mathrm{ZnSO}_{4}$ was added for deproteinization. This mixture was then centrifuged at $3000 \mathrm{~g}$ for 20 minutes and supernatants were used for the assays. Serum samples were deproteinized prior to assay. Serum was added to $96 \%$ cold ethanol $(1 / 2 \mathrm{v} / \mathrm{v})$ and then vortexed for $5 \mathrm{~min}$.

After incubation for 30 minutes at $4^{\circ} \mathrm{C}$, the mixture was centrifuged at 14,000 rpm for 5 minutes and the supernatants were used for the Griess assay $(37,40)$.

Data collected during the experiment were analyzed with SPSS 15 for Windows using t-Test for two independent samples. The data was expressed as mean \pm standard deviation and probability $(\mathrm{p})$ value less than 0.05 was accepted as statistically significant.

\section{RESULTS}

Mean tissue MDA level of the control group was measured as $3.18 \pm 0.63(\mathrm{nmol} / \mathrm{gr})$. Induction of ischemia increased this value to $5.09 \pm 0.84(\mathrm{nmol} / \mathrm{gr})$ in the l/R group. Mean tissue MDA level of the atorvastatin administered treatment group was $3.20 \pm 0.40(\mathrm{nmol} / \mathrm{gr})$. The difference between the I/R group and the treatment group was statistically significant $(p=0.001)$.

Mean tissue GSH level of the control group was $0.68 \pm 0.05$ (nmol/gr) and induction of ischemia decreased this level to $0.25 \pm 0.05$ (nmol/gr) in the I/R group. Mean tissue GSH level was measured as $0.66 \pm 0.10(\mathrm{nmol} / \mathrm{gr})$ in the treatment group.
The difference between the I/R group and the treatment group was statistically significant $(p<0.05)$.

Mean tissue $\mathrm{NO}$ levels of the control, I/R and treatment groups were $73.41 \pm 12.3,113.83 \pm 10.74$ and $85.23 \pm 14.95(\mathrm{nmol} / \mathrm{mgr})$ respectively. The difference between the $\mathrm{l} / \mathrm{R}$ and the treatment groups was statistically significant $(p<0.05)$.

The bar graph in Figure 1 demonstrates mean tissue levels of the measured agents.

Mean plasma MDA level of the control group was measured as $1.60 \pm 0.47(\mathrm{nmol} / \mathrm{ml})$. Administration of ischemia increased this value to $2.46 \pm 0.41(\mathrm{nmol} / \mathrm{ml})$ in the $\mathrm{I} / \mathrm{R}$ group. Mean plasma MDA level of the atorvastatin administered treatment group was $1.89 \pm 0.44(\mathrm{nmol} / \mathrm{ml})$. The difference between the $\mathrm{l} / \mathrm{R}$ group and the treatment group was statistically significant $(p=0.015)$.

Mean plasma GSH level of the control group was $352.68 \pm 54.13$ $(\mathrm{nmol} / \mathrm{ml})$ and induction of ischemia decreased this level to $233.15 \pm 29.66(\mathrm{nmol} / \mathrm{ml})$ in the l/R group.

Mean plasma GSH level was measured as $331.10 \pm 61.06$ $(\mathrm{nmol} / \mathrm{ml})$ in the treatment group. The difference between the $\mathrm{I} / \mathrm{R}$ group and the treatment group was statistically significant $(p=0.001)$.

Mean plasma NO levels of the control, I/R and treatment groups were $116.11 \pm 20.94,257.15 \pm 38.46$ and $67.86 \pm 20.44$ $(\mathrm{nmol} / \mathrm{ml})$, respectively. The difference between the I/R and the treatment groups was statistically significant $(p<0.05)$.

The bar graph in Figure 2 demonstrates the mean plasma levels of the measured agents.

Neurological status of the animals was evaluated at three different time points using Tarlov scale. The bar graph in Figure 3

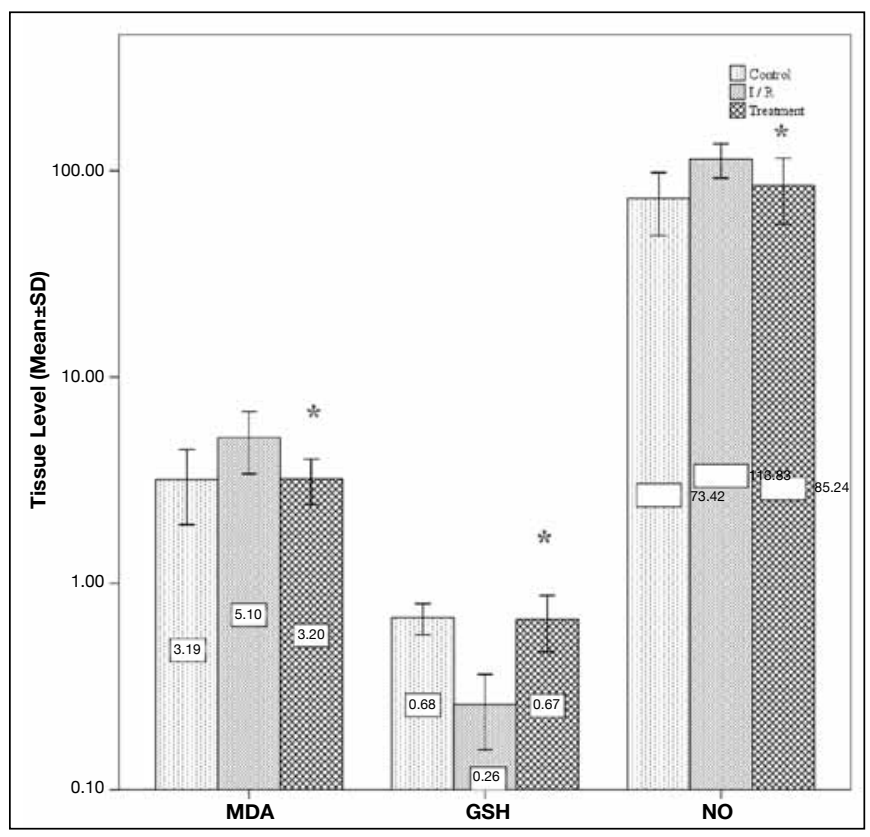

Figure 1: Bar graph demonstrating tissue levels of MDA, GSH and NO. ( ${ }^{*} p<0.05$ treatment group versus I/R group). 
and Table I demonstrates the evaluation results. Comparison of the $\mathrm{I} / \mathrm{R}$ and treatment groups regarding their Tarlov scale results at the $6^{\text {th }}$ and the $24^{\text {th }}$ hours did not reveal any significant results ( $p=0.098$ and $p=0.153$, respectively). On the other hand, evaluations performed at the $48^{\text {th }}$ hour demonstrated a significant difference between the $\mathrm{I} / \mathrm{R}$ and treatment groups in favor of the treatment group.

The mean Tarlov score of the treatment group at the $48^{\text {th }}$ hour was significantly higher than that of the $\mathrm{l} / \mathrm{R}$ group $(p=0.033)$.

All of the animals in the control group demonstrated normal histological structure. Neurons at the anterior horn of the spinal cord segments from the animals in the I/R group were significantly destroyed. Nearly $84 \%$ of the neurons were damaged in this group. Additionally, structural damage in the axons and the extent of glial cell infiltration was significant in this group. Axonal damage grading of all of the animals was Grade 2 and extent of the glial cell infiltration was consisted of $3+$ and $4+$.

On the other hand, observations demonstrated that atorvastatin administration to the treatment group animals have resulted in better histopathological results.

Nearly $45 \%$ of the neurons were destroyed in this group. Most of the axons were spared demonstrating Grade 1 degeneration. Extent of the glial cell infiltration was also milder in this group. Table II demonstrates the results of histopathological evaluation in groups. Figure 4A-D demonstrate sample specimens from the I/R group and the treatment group.

Table I: The Distribution of the Total Number of Groups of Rabbits according to the Tarlov Score

\begin{tabular}{llllllllll}
\hline Control & & \multicolumn{7}{c}{ Treatment } \\
\hline Tarlov Score & $6 \mathrm{~h}$ & $24 \mathrm{~h}$ & $48 \mathrm{~h}$ & $6 \mathrm{~h}$ & $24 \mathrm{~h}$ & $48 \mathrm{~h}$ & $6 \mathrm{~h}$ & $24 \mathrm{~h}$ & $48 \mathrm{~h}$ \\
\hline 0 & & & 6 & 4 & 5 & 3 & 2 & 2 \\
\hline 1 & & & 3 & 4 & 4 & 3 & 3 & 2 \\
\hline 2 & & & 1 & 2 & 1 & 2 & 4 & 4 \\
\hline 3 & & & & & & 2 & 1 & 2 \\
\hline 4 & 10 & 10 & 10 & & & & & & \\
\hline 5 & 5 & 5 & 5 & 0.5 & 0.8 & 0.6 & 1.3 & 1.4 & 1.6 \\
\hline Mean & & & & & & & & & \\
\hline
\end{tabular}

I/R: Ischemia and reperfusion, h: Hour.

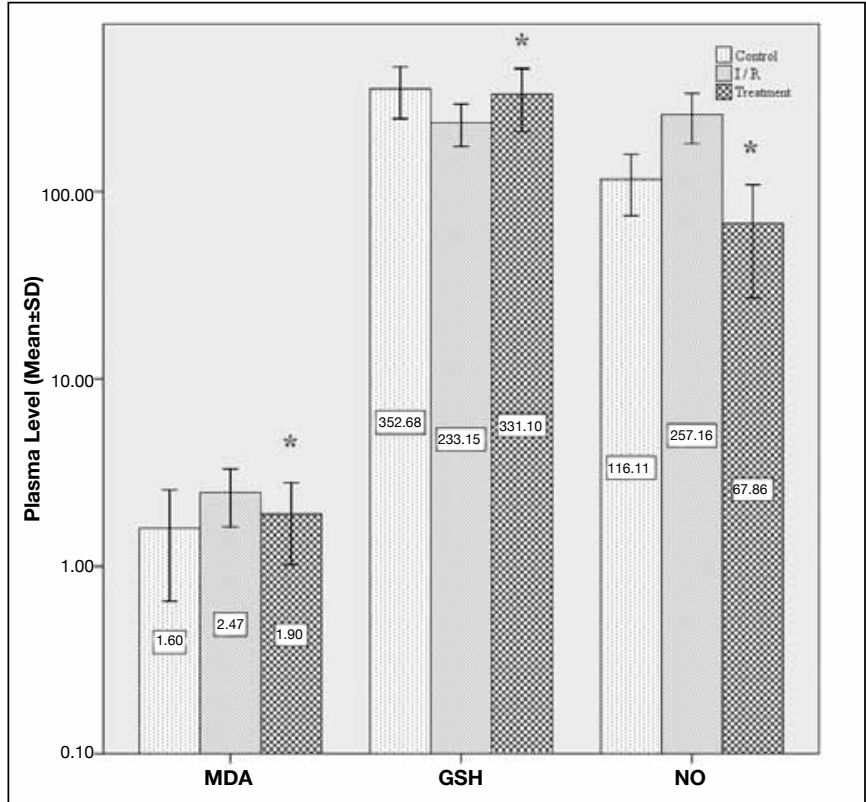

Figure 2: Bar graph demonstrating plasma levels of MDA, GSH and NO. ( ${ }^{*} \mathrm{p}<0.05$ treatment group versus $\mathrm{l} / \mathrm{R}$ group).

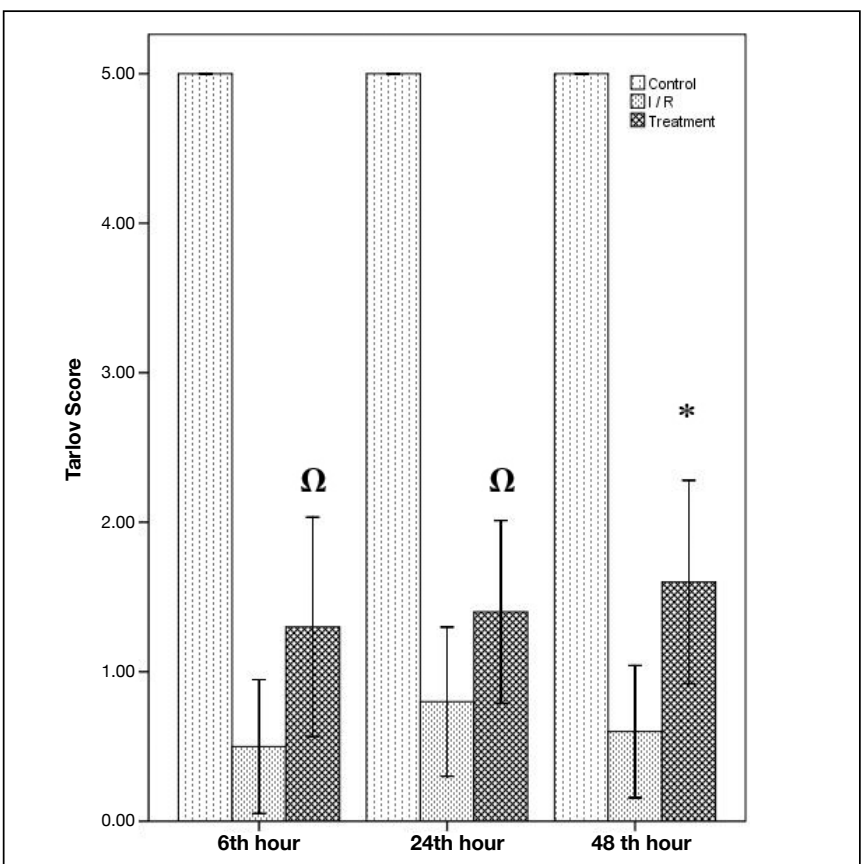

Figure 3: Bar graph demonstrating Tarlov scores of animals at $6^{\text {th }}$, $24^{\text {th }}$ and $48^{\text {th }}$ hour. $\left({ }^{*} \mathrm{p}<0.05\right.$ treatment group versus I/R group; $\Omega$ $\mathrm{p}>0.05$ treatment versus $\mathrm{I} / \mathrm{R}$ group). 
Kardes O. et al: Atorvastatin in Spinal Cord Injury

Table II: Results of Histopathological Evaluation

\begin{tabular}{c|ccc|ccc|ccc}
\hline & \multicolumn{3}{|c|}{ Control Group } & \multicolumn{3}{c|}{ I/R Group } & \multicolumn{2}{c}{ Treatment Group } \\
\hline Subject & $\begin{array}{c}\text { Damaged } \\
\text { Neurons }\end{array}$ & $\begin{array}{c}\text { Axonal } \\
\text { Damage }\end{array}$ & $\begin{array}{c}\text { Glial cell } \\
\text { infiltration }\end{array}$ & $\begin{array}{c}\text { Damaged } \\
\text { Neurons }\end{array}$ & $\begin{array}{c}\text { Axonal } \\
\text { Damage }\end{array}$ & $\begin{array}{c}\text { Glial cell } \\
\text { infiltration }\end{array}$ & $\begin{array}{c}\text { Damaged } \\
\text { Neurons }\end{array}$ & $\begin{array}{c}\text { Axonal } \\
\text { Damage }\end{array}$ & $\begin{array}{c}\text { Glial cell } \\
\text { infiltration }\end{array}$ \\
\hline $\mathbf{1}$ & $0 / 10$ & Grade 0 & + & $8 / 10$ & Grade 2 & +++ & $3 / 10$ & Grade 0 \\
\hline $\mathbf{2}$ & $0 / 10$ & Grade 0 & + & $9 / 10$ & Grade 2 & ++++ & $3 / 10$ & Grade 0 \\
\hline $\mathbf{3}$ & $0 / 10$ & Grade 0 & + & $9 / 10$ & Grade 2 & ++++ & $5 / 10$ & Grade 1 & ++ \\
\hline $\mathbf{4}$ & $0 / 10$ & Grade 0 & + & $7 / 10$ & Grade 2 & +++ & $4 / 10$ & Grade 0 & + \\
\hline $\mathbf{5}$ & $0 / 10$ & Grade 0 & + & $9 / 10$ & Grade 2 & ++++ & $6 / 10$ & Grade 1 \\
\hline $\mathbf{6}$ & $0 / 10$ & Grade 0 & + & $8 / 10$ & Grade 2 & +++ & $6 / 10$ & Grade 1 \\
\hline $\mathbf{7}$ & $0 / 10$ & Grade 0 & + & $9 / 10$ & Grade 2 & ++++ & $7 / 10$ & Grade 1 \\
\hline $\mathbf{8}$ & $0 / 10$ & Grade 0 & + & $8 / 10$ & Grade 2 & +++ & $5 / 10$ & Grade 1 \\
\hline $\mathbf{9}$ & $0 / 10$ & Grade 0 & + & $8 / 10$ & Grade 2 & +++ & $3 / 10$ & Grade 0 \\
\hline $\mathbf{1 0}$ & $0 / 10$ & Grade 0 & + & $9 / 10$ & Grade 2 & ++++ & $3 / 10$ & Grade 0 \\
\hline
\end{tabular}

I/R: Ischemia and reperfusion.

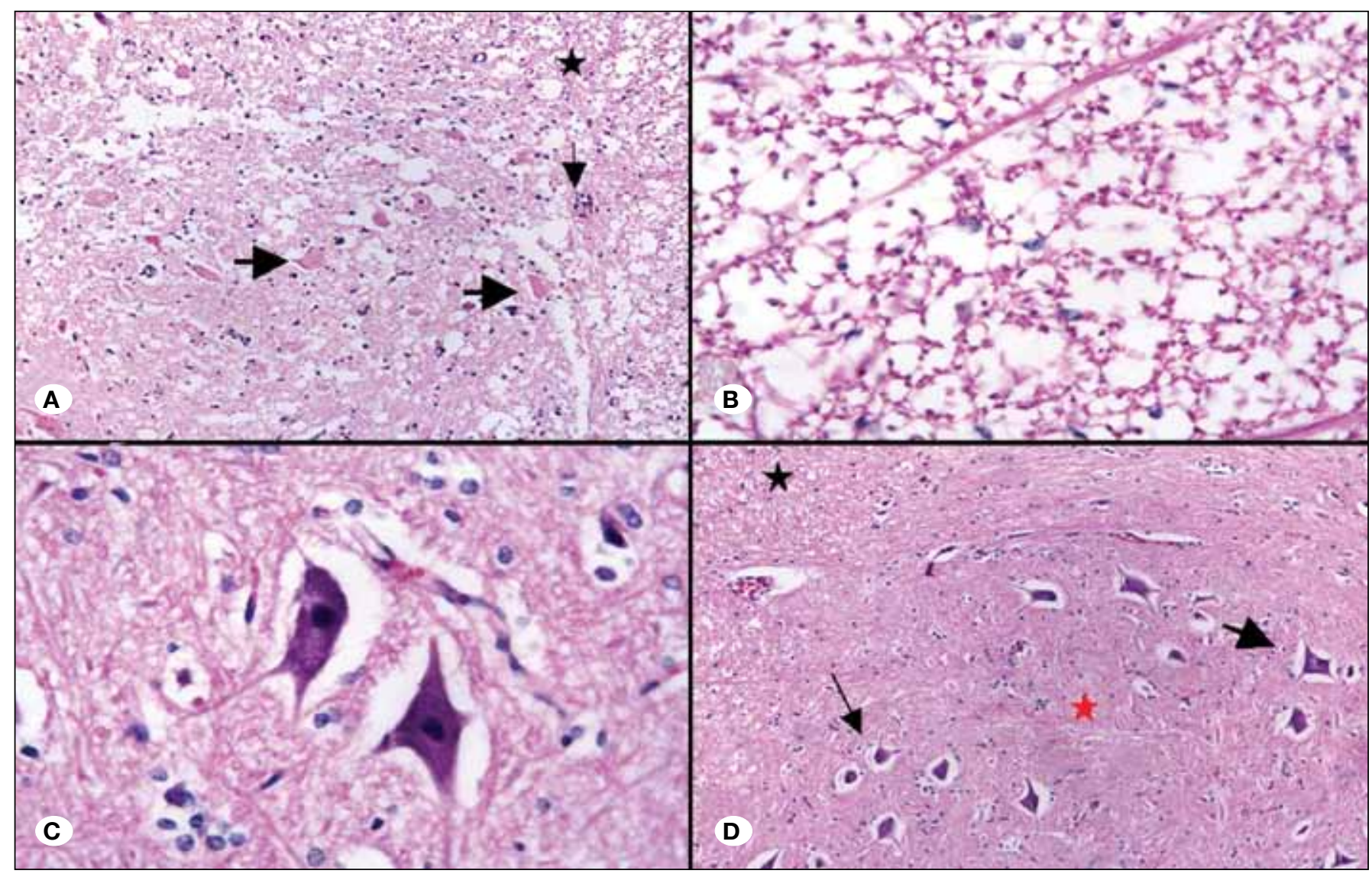

Figure 4: Photomicrograph demonstrating histopathological evaluation of injured neural tissues from the I/R group and the treatment group. A) A specimen from the I/R group. Motor neurons have lost their multipolarity with eosinophilic cytoplasms (thick arrow), degenerated white matter (thin arrow) and increased glial cell infiltration (star)(H\&E, x10). B) A specimen from the I/R group with white mater demonstrating severe axonal degeneration and vacuolization (H\&E, x40). C) A specimen from the treatment group demonstrating neurons with spared multipolarity and basophilic cytoplasm (thick arrow) with moderate glial cell infiltration (thin arrow)(H\&E, x40). D) Another slice from the treatment group demonstrating neurons with spared multipolarity and basophilic cytoplasm (thick and thin arrows) with moderate glial cell infiltration in white matter (black star) and gray matter (red star) (H\&E, x10). 


\section{DISCUSSION}

The pathophysiological mechanisms that underlie ischemic injury to the spinal cord have not been clearly elucidated. Extinction of blood supply leads to exhaustion of energy depot in the tissue. Energy expenditure triggers ischemic cascades and secondary damage ensues. The first event leading to cell destruction after ischemia is the depolarization and opening of voltage dependent ion channels (i.e. $\mathrm{Na}+, \mathrm{K}+, \mathrm{Ca}++)(23)$. This leads to massive release of neurotransmitters including glutamate, which causes the opening of glutamate receptoroperated ion channels.

Ionic disturbances lead to accumulation of intracellular $\mathrm{Ca}++$ and initiate damaging cascades. On the other hand reperfusion injury is another serious problem.

After the increase of blood flow (reperfusion) in the spinal cord, oxygen that is needed for production of uric acid is supplied from hypoxanthine. Reperfusion of the ischemic tissue leads to influx of excess amounts of oxygen through the tissue resulting in formation of free oxygen radicals. These oxygen radicals further aggravate tissue damage $(10,24,42)$. Glutamate-mediated calcium toxicity induced mitochondrial dysfunction and the associated loss of energy supply together with formation of free oxygen radicals are important targets of spinal cord injury studies (36). These radicals react with the cellular lipids and mitochondrial membranes and produce lipid peroxides. The lipid peroxidation of membranes causes membrane and cell damage. This process is called "reperfusion injury" (46).

Some therapeutic modalities that limit oxidative stress may have potential benefit over several neurological diseases. Corticosteroids, lazaroids, gangliosides, calcium channel blockers, free radical scavengers, magnesium, sodium channel blockers, cyclosporin A, opioid receptor antagonists, Nmethyl-D-aspartate (NMDA) receptor antagonists, and thyrotropin-releasing hormone have been shown to be effective in experimental SCl models. In-vivo and in-vitro neuroprotective effects of NMDA and non-NMDA receptor antagonists have been shown, however their clinical use is being limited by their major adverse effects (17).

Another therapeutic agent group that examined for neuronal protection is HMG CoA-reductase inhibitors. Today, the anti-inflammatory and neuroprotective efficacy of HMG CoAreductase inhibitors in experimental models of diseases such as Alzheimer's, multiple sclerosis and cerebral ischemic injury has been proven $(7,19,41)$. The anti-inflammatory effects of these statins are the result of their inhibitory effects on adhesion molecules and cell proliferation mediators (particularly $\mathrm{T}$ cell proliferation and consequent cytokine proliferation). They preclude adhesion of inflammatory cells to the endothelial surface.

Statins also inhibit antigen presentation by antigen presenting cells in the peripheral circulation $(34,50,51)$. Additionally, statins pose anti-oxidant features by both inhibiting low-density lipoprotein oxidation and by inhibiting destruction of nitric oxide by free oxygen radicals (28). In their in vitro studies, Franzoni et al. have proved antioxidant activities of statins (20).
Atorvastatin was also studied for spinal cord injury and the preventive effects on apoptosis were proven before (15). Neuroprotective effects of atorvastatin were well known entity (35). The possible effects of atorvastatin on neuronal injury are maintaining the integrity of blood brain barrier, lowering tumor necrosis factor (TNF)- $\alpha$, Interleukin (IL)-1 $\beta$ levels and suppressing inducible nitric oxide synthase (iNOS) activity $(13,15,35,42)$. Besides these, same suppressive activity on microglia was demonstrated. These pathways are lowering the neuroinflammation. Also favourable effects of atorvastatin on neuropathic pain was proven by two studies $(13,42)$.

As far as we are aware, the neuroprotective effect of atorvastatin in spinal cord I/R injury has been evaluated before and two studies were published. They conclude that pretreatment therapy of atorvastatin was also effective for I/R injury $(26,39)$. Anti-inflammatory, antioxidant, and neuroprotective effects are discussed as possible mechanisms.

In our study, we evaluated the effects of atorvastatin pretreatment after experimentally induced spinal cord ischemiareperfusion injury model on oxidative stress markers by evaluating MDA, GSH and NO levels. Additionally, we evaluated the histological and functional outcomes of the treatment.

High lipid concentration of the nervous system makes it vulnerable to the hydroxyl radicals and lipid peroxidation (30). Lipid peroxidation aggravates spinal cord hypoperfusion, edema formation, axonal conduction failure and disturbances of energy failure $(8,22)$.

To evaluate the extent of the peroxidation reaction, MDA, which is formed from the breakdown of polyunsaturated fatty acids, is used (44).

An increase in lipid peroxidation in $\mathrm{I} / \mathrm{R}$ injury of the spinal cord and serum has been shown following aortic clamping in the recent studies $(45,49)$. Increase in MDA levels following 30 minutes of reperfusion in patients who undergo coronary artery surgery have been shown by Belboul et al (6). However, Nazli et al. showed increase in MDA levels (39). In our study, a significant increase of MDA levels was observed after ischemia-reperfusion in the control group. Also, subjects receiving atorvastatin had significantly lower tissue and plasma MDA levels compared to the I/R group. After an I/R injury, MDA levels increase and lipid peroxidation occurs, thus the presence of reperfusion injury is supported. Similar to previous studies, our study showed a significant increase in MDA levels after I/R injury (39).

Glutathione is one of the principle endogenous anti-oxidant molecules and plays an important role in neutralization of free radicals and reactive oxygen species The decrease in GSH level increases oxidative stres (49). Aydemir et al. have reported a decreased GSH levels at reperfusion by melatonin administration. In our study, administration of atorvastatin significantly increased the level of GSH both in plasma and neural tissue (1).

Nitric oxide is a gas known to induce macrophage cytotoxicity and has important roles in neural signaling. It has been demonstrated that high $\mathrm{NO}$ concentrations increases oxida- 
tive stress. After spinal cord injury, expression of NO synthase -a catalyzer of NO synthesis- increases. Excessive NO has cytotoxic effects and induces neuronal apoptosis, neuronal degeneration and dysfunction $(14,25,32)$. Our results demonstrated that the $1 / R$ injury significantly increased the NO level both in the tissue and the plasma. Administration of atorvastatin to the animals in the treatment group significantly decreased these levels.

Nitric oxide dilates the vessels, induces macrophage cytotoxicity and plays a role in neural signaling. It is a unique molecule playing a role in many physiological processes of the CNS. Its protective and destructive effects have been shown in several neurological disorders. Lower NO concentration has been proven to have an important part in physiological processes, and higher levels to increase oxidative stress. Inducible NO synthase is expressed in the spinal cord immediately after SCl. Synthesis of large NO amounts has cytotoxic effects and leads to neuronal dysfunction, secondary neural degeneration and neuronal apoptosis $(14,25,32,47)$. Emmez et al. performed a study on the effects of alpha-lipoic acid on spinal cord reperfusion injury in rabbits and they demonstrated that $\mathrm{NO}$ levels increased both in the tissue and the plasma after the I/R injury. In addition, administration of alpha-lipoic acid significantly decreased these levels. Our study showed similar results with this study (17).

Similar promising results were also gathered after histopathological evaluation. The primary injury is followed by post-insult inflammation, in which inflammatory cells such as neutrophils, macrophages and resident microglia accumulate at the injury site (38). The mediators released by these cells increase the tissue damage. Similar to the studies of Hwang et al. and Ucak et al. on simvastatin, histopathological evaluation of the injured tissues in atorvastatin administered subjects in our study demonstrated less injury than the subjects in the $\mathrm{I} / \mathrm{R}$ group $(27,48)$. We concluded that this favorable effect has been also reflected, and is the result of better neurological outcome scores in the atorvastatin receiving group, as demonstrated in our study (Figure 3).

In current clinical practice, statins are used over a long time period to obtain benefit from their anti-lipidemic and cardioprotective properties. In our study, the significantly better results with the administration of atorvastatin prior to surgery appear to support those data (4). These data corroborate the neuroprotective effects of atorvastatin, similar to the literature. However, the neurological damage caused by vascular complications is still a major issue and pre-treatment with atorvastatin has promising effects on spinal $\mathrm{l} / \mathrm{R}$ injury.

\section{- CONCLUSION}

We believe that atorvastatin has favorable effects in the spinal cord ischemia reperfusion injury model in rabbits. Further experimental studies with larger cohorts and at different time points should be performed to project these findings to clinical settings.

\section{REFERENCES}

1. Aydemir S, Dogan D, Kocak A, Dilsiz N: The effect of melatonin on spinal cord after ischemia in rats. Spinal Cord 54(5):360363, 2016

2. Aykac G, Uysal M, Yalcin AS, Kocak-Toker N, Sivas A, Oz H: The effect of chronic ethanol ingestion on hepatic lipid peroxide, glutathione, glutathione peroxidase and glutathione transferase in rats. Toxicology 36:71-76, 1985

3. Azbill RD, Mu X, Bruce-Keller AJ, Mattson MP, Springer JE: Impaired mitochondrial function, oxidative stress and altered antioxidant enzyme activities following traumatic spinal cord injury. Brain Res 765:283-290, 1997

4. Baigent C, Keech A, Kearney PM, Blackwell L, Buck G, Pollicino C, Cholesterol Treatment Trialists' (CTT) Collaborators: Efficacy and safety of cholesterol lowering treatment: Prospective metaanalysis of data from 90.056 participants in 14 randomized trials of statins. Lancet 366:1267-1278, 2005

5. Baptiste DC, Fehlings MG: Pharmacological approaches to repair the injured spinal cord. J Neurotrauma 23:318-334, 2006

6. Belboul A, Roberts D, Borjesson R, Johnsson J: Oxygen free radical generation in healthy blood donors and cardiac patients: The protective effect of allopurinol. Perfusion 16:59-65, 2001

7. Bosel J, Gandor F, Harms C, Synowitz M, Harms U, Djoufack PC, Megow D, Dirnagl U, Hortnagl H, Fink KB, Endres $M$ : Neuroprotective effects of atorvastatin against glutamateinduced excitotoxicity in primary cortical neurones. J Neurochem 92:1386-1398, 2005

8. Carlson GD, Gorden C: Current developments in spinal cord injury research. Spine J 2:116-128, 2002

9. Casini A, Ferrali M, Pompelam A, Maellaro E, Comporti M: Lipid peroxidation and cellular damage in extrahepatic tissues of bromobenzene intoxicated mice. Am J Pathol 123:520531, 1986

10. Chan $\mathrm{PH}$ : Role of oxidants in ischemic brain damage. Stroke 27:1124-1129, 1996

11. Cheng MK, Robertson C, Grossman RG, Foltz R, Williams V: Neurological outcome correlated with spinal evoked potentials in a spinal cord ischemia model. J Neurosurg 60:786-795, 1984

12. Christie SD, Comeau B, Myers T, Sadi D, Purdy M, Mendez I: Duration of lipid peroxidation after acute spinal cord injury in rats and the effect of methylprednisolone. Neurosurg Focus 25:E5, 2008

13. Chu LW, Chen JY, Wu PC, Wu BN: Atorvastatin prevents neuroinflammation in chronic constriction injury rats through nuclear NFKB downregulation in the dorsal root ganglion and spinal cord. ACS Chem Neurosci 6:889-898, 2015

14. Conti A, Miscusi M, Cardali S, Germano A, Suzuki H, Cuzzocrea S, Tomasello F : Nitric oxide in the injured spinal cord: Synthases cross-talk, oxidative stress and inflammation. Brain Res Rev 54:205-218, 2007

15. Déry MA, Rousseau G, Benderdour M, Beaumont E: Atorvastatin prevents early apoptosis after thoracic spinal cord contusion injury and promotes locomotion recovery. Neurosci Lett 453:73-76, 2009 
16. Dumont RJ, Okonkwo DO, Verma S, Hurlbert RJ, Boulos PT, Ellegala DB, Dumont AS: Acute spinal cord injury, part I: Pathophysiologic mechanisms. Clin Neuropharmacol 24:254264, 2001

17. Emmez H, Yildirim Z, Kale A, Tonge M, Durdag E, Borcek AO, Ucankus LN, Dogulu F, Kilic N, Baykaner MK: Anti-apoptotic and neuroprotective effects of alpha-lipoic acid on spinal cord ischemia-reperfusion injury in rabbits. Acta Neurochir 152:1591-1601, 2010

18. Erten SF, Kocak A, Ozdemir I, Aydemir S, Colak A, Reeder BS: Protective effect of melatonin on experimental spinal cord ischemia. Spinal Cord 41:533-538, 2003

19. Franke C, Noldner M, Abdel-Kader R, Johnson-Anuna LN, Gibson Wood W, Muller WE, Eckert GP: Bcl-2 upregulation and neuroprotection in guinea pig brain following chronic simvastatin treatment. Neurobiol Dis 25:438-445, 2007

20. Franzoni F, Quiñones-Galvan A, Regoli F, Ferrannini E, Galetta F: A comparative study of the in vitro antioxidant activity of statins. Int J Cardiol 90:317-321, 2003

21. Gunasekar PG, Kanthasamy AG, Borowitz JL, Isom GE: NMDA receptor activation produces concurrent generation of nitric oxide and reactive oxygen species: Implication for cell death. J Neurochem 65:2016-2021, 1995

22. Hall ED, Braughler JM: Free radicals in CNS injury. Res Publ Assoc Res Nerv Ment Dis 71:81-105, 1993

23. Hall ED, Springer JE: Neuroprotection and acute spinal cord injury: A reappraisal. NeuroRx 1:80-100, 2004

24. Hausmann ON: Post-traumatic inflammation following spinal cord injury. Spinal Cord 41:369-378, 2003

25. Hosaka N, Kimura S, Yamazaki A, Wang X, Denda H, Ito T, Hirano T, Endo N: Significant correlation between cerebrospinal fluid nitric oxide concentrations and neurologic prognosis in incomplete cervical cord injury. Eur Spine J 17:281-286, 2008

26. Hu JR, Lv GH, Yin BL: Altered microRNA expression in the ischemic-reperfusion spinal cord with atorvastatin therapy. J Pharmacol Sci 121:343-346, 2013

27. Hwang J, Han JI, Han S: Effect of pretreatment with simvastatin on spinal cord ischemia-reperfusion injury in rats. J Cardiothorac Vasc Anesth 27:79-85, 2013

28. Jorge PA, Osaki MR, de Almeida E: Rapid reversal of endothelial dysfunction in hypercholesterolaemic rabbits treated with simvastatin and pravastatin. Clin Exp Pharmacol Physiol 24:948-953, 1997

29. Jung KH, Chu K, Jeong SW, Han SY, Lee ST, Kim JY, Kim M, Roh JK: HMG-CoA reductase inhibitor, atorvastatin, promotes sensorimotor recovery, suppressing acute inflammatory reaction after experimental intracerebral hemorrhage. Stroke 35:1744-1749, 2004

30. Kalayci M, Coskun O, Cagavi F, Kanter M, Armutcu F, Gul S, Acikgoz B: Neuroprotective effects of ebselen on experimental spinal cord injury in rats. Neurochem Res 30:403-410, 2005

31. Kale A, Borcek AO, Emmez H, Yildirim Z, Durdag E, Lortlar N, Kurt G, Dogulu F, Kilic N: Neuroprotective effects of gabapentin on spinal cord ischemia-reperfusion injury in rabbits. $J$ Neurosurg Spine 15:228-237, 2011
32. Kimura S, Hosaka N, Yuge I, Yamazaki A, Suda K, Taneichi H, Denda $\mathrm{H}$, Endo N: Cerebrospinal fluid concentrations of nitric oxide metabolites in spinal cord injury. Spine 34:645-652, 2009

33. Kurtel H, Granger DM, Tso P, Grisham MB: Vulnerability of intestinal interstitial fluid to oxidant stress. Am J Physiol 263:573-578, 1992

34. Kwak B, Mulhaupt F, Myit S, Mach F: Statins as a newly recognized type of immunomodulator. Nat Med 6:1399-1402, 2000

35. Li F, Fei D, Sun L, Zhang S, Yuan Y, Zhang L, Zhao K, Li R, Yu $Y$ : Neuroprotective effect of bone marrow stromal cell combination with atorvastatin in rat model of spinal cord injury. Int $\mathrm{J}$ Clin Exp Med 7:4967-4974, 2014

36. Markovic-Plese S, Singh AK, Singh I: Therapeutic potential of statins in multiple sclerosis: Immune modulation, neuroprotection and neurorepair. Future Neurol 3:153-167, 2008

37. Miranda KM, Espey MG, Wink DA: A rapid, simple spectrophotometric method for simultaneous detection of nitrate and nitrite. Nitric Oxide 5:62-71, 2001

38. Mukaino M, Nakamura M, Yamada O, Okada S, Morikawa S, Renault-Mihara F, Iwanami A, Ikegami T, Ohsugi Y, Tsuji O, Katoh H, Matsuzaki Y, Toyama Y, Liu M, Okano H: AntiIL-6-receptor antibody promotes repair of spinal cord injury by inducing microglia-dominant inflammation. Exp Neurol 224:403-414, 2010

39. Nazli Y, Colak N, Alpay MF, Uysal S, Uzunlar AK, Cakir O: Neuroprotective effect of atorvastatin in spinal cord ischemiareperfusion injury. Clinics (Sao Paulo) 70:52-60, 2015

40. Oz Oyar E, Kardes O, Korkmaz A, Omeroglu S: Effects of vascular endothelial growth factor on ischemic spinal cord injury caused by aortic cross-clamping in rabbits. J Surg Res 151:94-99, 2009

41. Pannu R, Christie DK, Barbosa E, Singh I, Singh AK: Posttrauma Lipitor treatment prevents endothelial dysfunction, facilitates neuroprotection, and promotes locomotor recovery following spinal cord injury. J Neurochem 101:182-200, 2007

42. Pathak NN, Balaganur V, Lingaraju MC, More AS, Kant V, Kumar D, Kumar D, Tandan SK: Antihyperalgesic and antiinflammatory effects of atorvastatin in chronic constriction injury-induced neuropathic pain in rats. Inflammation 36:14681478, 2013

43. Peters O, Back T, Lindauer U, Busch C, Megow D, Dreier J, Dirnagl U: Increased formation of reactive oxygen species after permanent and reversible middle cerebral artery occlusion in the rat. J Cereb Blood Flow Metab 18:196-205, 1998

44. Qian H, Liu D: The time course of malondialdehyde production following impact injury to rat spinal cord as measured by microdialysis and high pressure liquid chromatography. Neurochem Res 22:1231-1236, 1997

45. Tapia-Pérez J, Sanchez-Aguilar M, Schneider T: The role of statins in neurosurgery. Neurosurg Rev 33:259-270, 2010

46. Temiz C, Solmaz I, Tehli O, Kaya S, Onguru O, Arslan E, Izci Y: The effects of splenectomy on lipid peroxidation and neuronal loss in experimental spinal cord ischemia/reperfusion injury. Turk Neurosurg 23:67-74, 2013 
47. Tsai SK, Hung LM, Fu YT, Cheng H, Nien MW, Liu HY, Zhang FBY, Huang SS: Resveratrol neuroprotective effects during focal cerebral ischemia injury via nitric oxide mechanism in rats. J Vasc Surg 46:346-353, 2007

48. Ucak A, Onan B, Guler A, Sahin MA, Kilickaya O, Oztas E, Uysal B, Arslan S, Yılmaz AT: Rosuvastatin, a new generation 3-hydroxy-3-methylglutaryl coenzyme a reductase inhibitor, reduces ischemia/reperfusion-induced spinal cord tissue injury in rats. Ann Vasc Surg 25:686-695, 2011
49. Varija D, Kumar KP, Reddy KP, Reddy VK: Prolonged constriction of sciatic nerve affecting oxidative stressors \& antioxidant enzymes in rat. Indian J Med Res 129:587-592, 2009

50. Vaughan CJ, Delanty N: Neuroprotective properties of statins in cerebral ischemia and stroke. Stroke 30:1969-1973, 1999

51. Youssef S, Stuve O, Patarroyo JC, Ruiz PJ, Radosevich JL, Hur EM, Bravo M, Mitchell DJ, Sobel RA, Steinman L, Zamvil SS: The HMG-CoA reductase inhibitor atorvastatin, promotes a Th2 bias and reverses paralysis in central nervous system autoimmune disease. Stroke 30:1969-1973, 1999 